\title{
Implantología post-extracción inmediata: protocolo operativo y evaluaciones oclusales, periodontales y estéticas
}

\author{
CACCIANIGA GL * \\ CALZAVARA D ** \\ BALDINI A $* * *$ \\ BALDONI RMI **** \\ BASCONES A $* * * * *$
}

Caccianiga GL, Calzavara D, Baldini A, Baldoni RM, Bascones A. Implantología post-extracción inmediata: protocolo operativo y evaluaciones oclusales, periodontales y estéticas. Av Periodon Implantol. 2003; 15, 2: 69-75.

\begin{abstract}
RESUIMEN
OBJETIVO DEL TRABAJO: Evaluar la eficacia clínica del protocolo quirúrgico relativo a la colocación inmediata del tornillo en el alveolo post-extrativo.

MATERIAL Y MÉTODOS: Han sido evaluados, según los criterios de Albrekston y Buser 45 implantes colocados con la técnica post-extractiva, a los 6 meses y a los 3 años tras la colocación del implante.

RESULTADOS: El protocolo aplicado se ha demostrado válido, los porcentajes de éxito han sido parecidos con aquellos de la técnica tradicional, con la ventaja de disminuir notablemente el tiempo para la rehabilitación oclusal y con importantes ventajas estéticas para el paciente.

CONCLUSIONES: Con este nuevo protocolo quirúrgico implantológico se puede garantizar un elevado porcentaje de éxito con una importante disminución de los tiempos de intervención con mayores ventajas estéticas, funcionales y oclusales.
\end{abstract}

\section{PALABRÁS CLAVE}

Implante, alveolo, estética.

\section{INTRODUCCIÓN}

El implante inmediato post-extractivo se define como la colocación de un implante al mismo tiempo que la exodoncia.

Este protocolo quirúrgico se aleja del protocolo terapéutico tradicional clásico propuesto por Branemark que contemplaba la colocación del implante tras 7-8 meses de la exodoncia del diente natural.

Según Adell, Lekholm (1) para obtener la osteointegración hubiese sido necesario esperar desde los 4 hasta los 6 meses, sin carga protésica. Adell y Lekholm pensaban que un posible micro movimiento entre el implante endóseo y el hueso, hubiese deter-

\footnotetext{
* Profesor a contrato de Medicina y Quirurgía, Università degli Studi di Milano-Bicocca.

** Odontólogo y Master Periodoncia Universidad Complutense.

*** Odontólogo frequentador.

**** Tutor Medicina y Quirurgía Facoltà; Università degli Studi di Milano-Biococca.

****** Catedrático de Medicina Bucal y Periodoncia. Universidad Complutense de Madrid.
} 


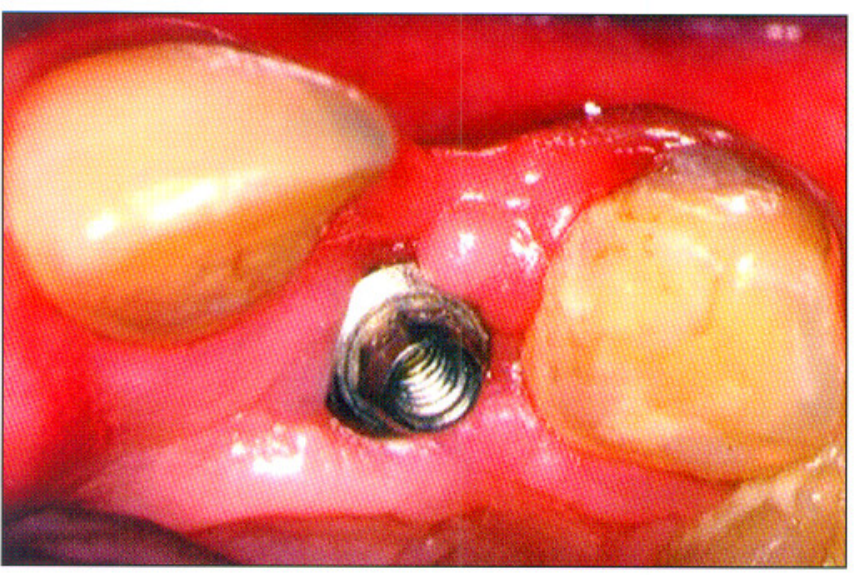

Fig. 1: Aplicación de una membrana reasorbible (Caso clínico $n^{\circ} 1$ )

minado una proliferación del tejido conectivo y un encapsulamiento fibroso del implante con la consecuente falta de la osteointegración del mismo. La colocación del implante en un lecho post-extractivo es una técnica relativamente nueva que se ha desarrollado en los últimos 10 años. Las exigencias fundamentales que han llevado al nacimiento de este protocolo, se origina de la exigencia de recortar los tiempos de la terapia, pero sobre todo por la necesidad de preservar las estructuras alveolares que están destinadas a un proceso de reabsorción, tras la exodoncia del elemento dentario (2).

Tras la avulsión dentaria se desarrollan unas series de numerosos procesos biológicos: reabsorción ósea tanto en el sentido vertical que en el horizontal, con modificación de la altura y del espesor del hueso alveolar, colapso gingival, movimientos migratorios de los dientes vecinos, modificación de la calidad ósea con colapso del hueso compacto y la formación de hueso alveolar medular (3).

En este intervalo de tiempo (seis meses) que pasa entre la avulsión del elemento dentario y la colocación del implante, se verifica la mayor cantidad de reabsorción ósea y de remodelación gingival (4) que suelen ser la causa de un daño biológico, estético y funcional. Finalizados los proceso de remodelación del alveolo difícilmente este último presenta un diámetro adecuado para el implante, obstaculizando por lo tanto en varias ocasiones la posibilidad de realizar un tratamiento implantológico (Fig. 1). Podemos apreciar como la falta de la colocación inmediata del implante, tras la avulsión del residuo radicular fracturado, haya llevado al posicionamiento del implante con una orientación anatómica obligada y que por lo tanto se la causa de la presencia de proyecciones coronales sobrecontorneadas con resultados estéticos dudosos y de complicado mantenimiento periodontal (Fig. 2).

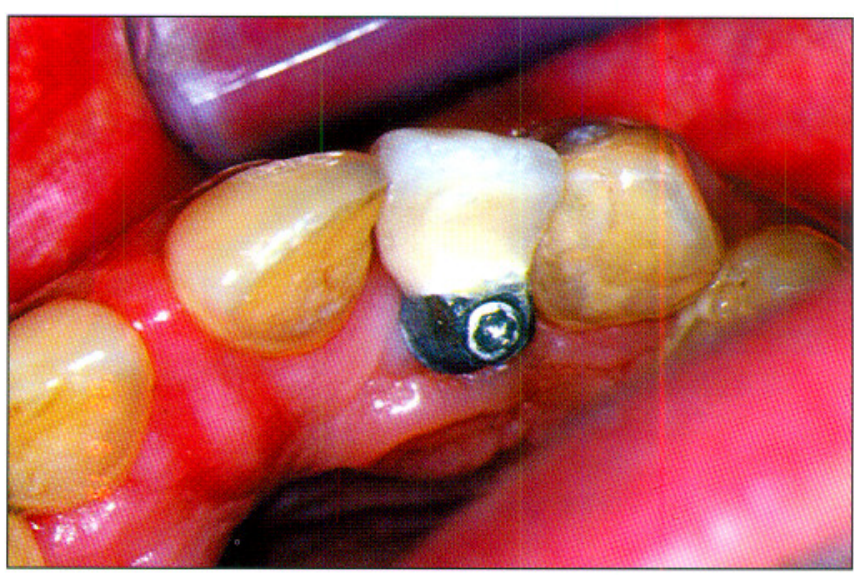

Fig. 2: Conexión con una barra y realización de la prótesis (Caso clí$\operatorname{nico} n^{\circ} 1$ )

La implantología post-extractiva soluciona este inconveniente, facilitando el mantenimiento de casi toda le estructura alveolar presente antes de la exodoncia.

El tejido óseo está compuesto por una matriz extracelular constituida aproximadamente de un $65 \%$ de material inorgánico y aproximadamente por un $25 \%$ de material orgánico. Las familias celulares que se encuentran en la matriz son de origen conectivo. Estas contemplan las células óseas no-diferenciadas desde las cuales se originan sucesivamente los osteoblastos, estas últimas serán los responsables de la formación del nuevo tejido óseo y los osteclastos, que serán responsables de la reabsorción ósea. El componente orgánico (35\%) de la matriz esta prevalentemente representada por las proteínas, que modulan la replicación celular regulando el proceso de remodelación. Entre estas últimas las principales son: los factores de crecimiento (producido por los osteoblastos) y las proteínas morfogenéticas del hueso (BMPl, BMP2A Y 2B, 3B). De este grupo, la proteína OF (osteoconductive factor) favorece la formación de hueso ectópico. Es oportuno mencionar también que las glicoproteínas no-colágenas están siempre presentes en la parte extracelular realizando un papel fundamental en la remodelación ósea.

Entre éstas merece la pena mencionar la fosfatasa alcalina, isoenzima producida por los osteoblastos y por los jóvenes osteocitos, con la posible función de inducir un aumento en la concentración de fosfatasas en el hueso, activando su transporte y favoreciendo la precipitación de la hidroxiapatita. El hueso en condiciones fisiológicas es una estructura compleja y su continua remodelación se realiza por la actividad bien equilibrada entre osteoclastos y osteoblastos, que compensados el uno con el otro mantienen el turnover constante.

Está claro por lo tanto que la colocación del implante 
inmediato en el alveolo, lleva una serie de ventajas que se traducen en una mejoría de la terapia y del resultado sea por un aspecto estético que funcional. En estos últimos años han sido realizados numerosos estudios multicéntricos sobre los implantes inmediatos. Especialmente en este último trabajo, Becker (5) ha evaluado el porcentaje de éxito a los 3 años de 49 implantes colocados con un protocolo post-extractivo y sus resultados evidencian un éxito del 93,9\%, la entidad de la neoformación ósea dependía de la exposición de la membrana (implantes sumergidos). Se han realzados muchos estudios de metodología y clínicos, con el objetivo de evaluar la curación de los implantes transmucosos inmediatos monofásicos $(6,7$, $8,9,10)$ y los resultados presentan porcentajes de éxito equiparables a las de los implantes sumergidos.

\section{MATERIAL Y MÉTODOS}

Se han incluido en la experimentación 42 pacientes, 24 mujeres y 18 varones, con una edad media de 41 años (entre los 24 y los 63 años), se han excluido los fuertes fumadores (más de diez cigarrillos/ día), mientras se han incluido los pacientes afectos de enfermedades metabólicas (diabetes) pero compensadas. Se han colocados según un protocolo que contemplaba un sola fase quirúrgica, un total de 45 implantes (15 Calcitek Spline, 15 Parogon Sulzer, 15 ITI con superficie SLA), de estos 22 eran de la longitud de $10 \mathrm{~mm}, 18$ de longitud de $12 \mathrm{~mm}$ y 5 de longitud de $14 \mathrm{~mm}$. El diámetro de los implantes era variable entre 3,75 y $4,1 \mathrm{~mm}$.

Hemos adoptado el protocolo quirúrgico propuesto por Lindhe en el 1994 y por lo tanto hemos considerado imprescindibles para poder conseguir un resultado clínico positivo los siguientes factores: ausencia de inflamación activa, mantenimiento de los márgenes óseos del alveolo durante la exodoncia, conseguir la estabilidad primaria de implante, riguroso control de placa durante la curación. En 17 implantes hemos tenido que colocar también una membrana de tipo reabsorbible y hueso bovino (Figs. 3 a 18). En 24 implantes se ha tenido que colocar solo el hueso de tipo bovino; en 4 implantes no se ha tenido que colocar ni la membrana ni el hueso.

Todos los pacientes que se han incluido en el estudio han sido visitados por un periodoncista experto, con la finalidad de establecer su situación periodontal y el $48 \%$ de ellos presentaba un valor de PSR (Periodontal Screening and Recording) $>3$, con una profundidad de sondaje $>=3,5 \mathrm{~mm}$ en por lo menos un sextante. Los pacientes han seguido un protocolo estándar de terapia periodontal etiológica, reevaluación y mante- nimiento con la finalidad de conseguir un estado de salud periodontal por lo menos dos meses antes de la colocación de lo implantes. El periodo de seguimien-

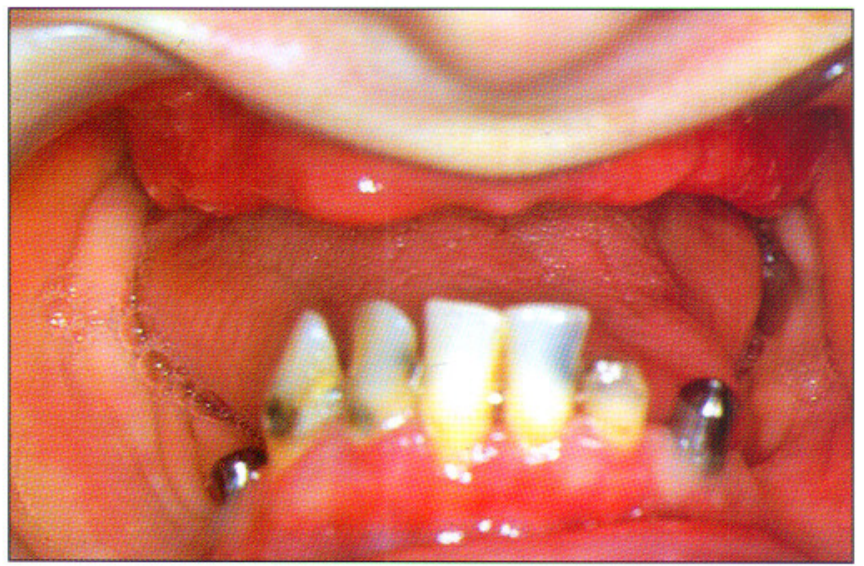

Fig. 3: 11 y el 12 tienen pronóstico imposible y no se pueden mantener (Caso clínico $n^{\circ} 2$ )

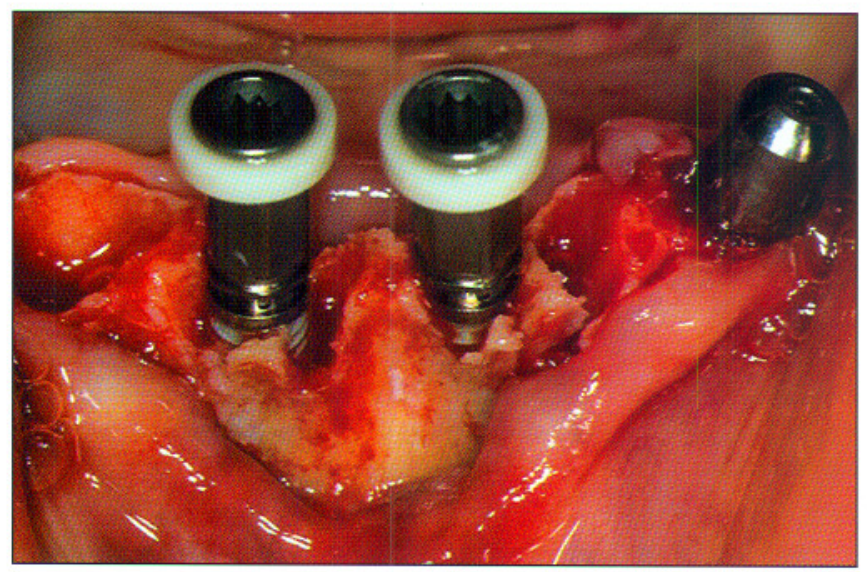

Fig. 4: Proyecciones coronales sobrecontorneadas con resultados estéticos dudosos y de complicado mantenimiento periodontal.

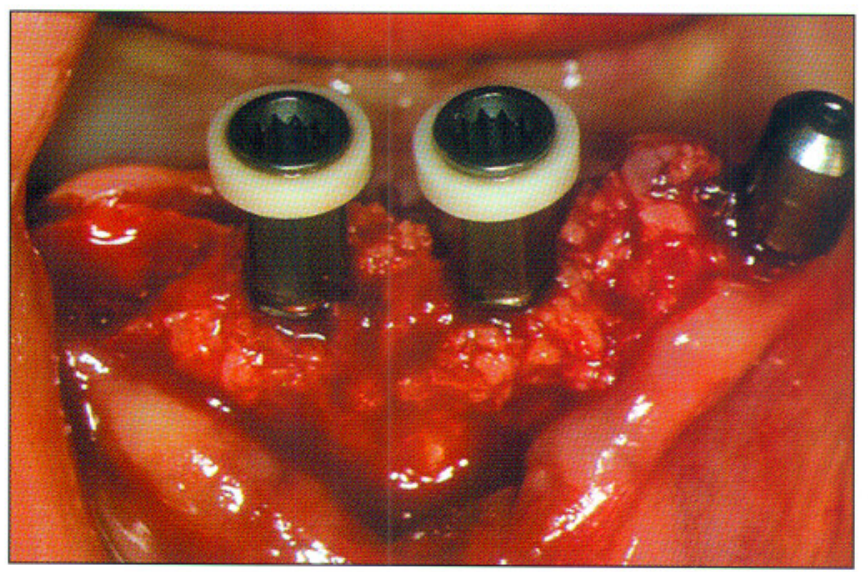

Fig. 5: El 31 y el 41 están comprometidos a nivel periodontal (Caso clínico $n^{\circ} 1$ ) 


\section{AVANCES}

Volumen 15 - $\mathrm{N}^{\circ} 2$ - Agosto 2003

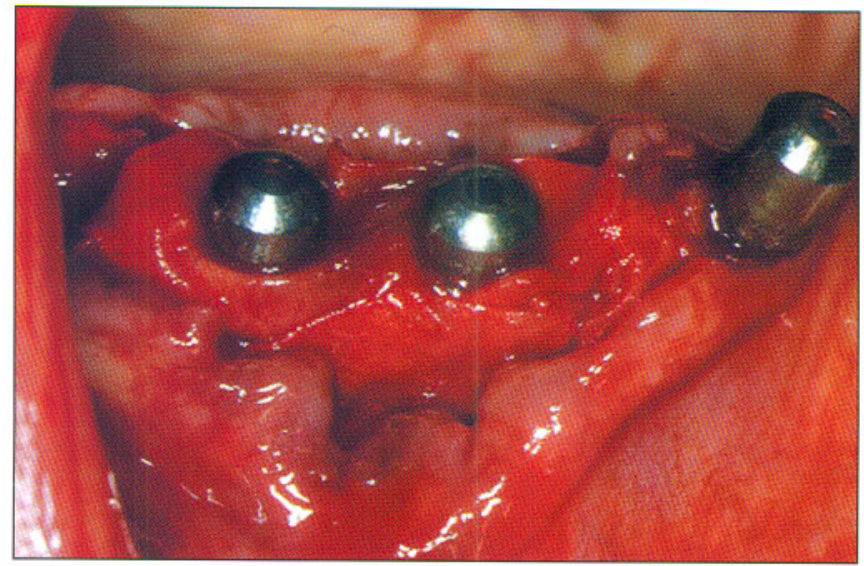

Fig. 6: Colocación de los tornillos en los alvéolos postestractivos (Caso clínico $n^{\circ} 2$ ).

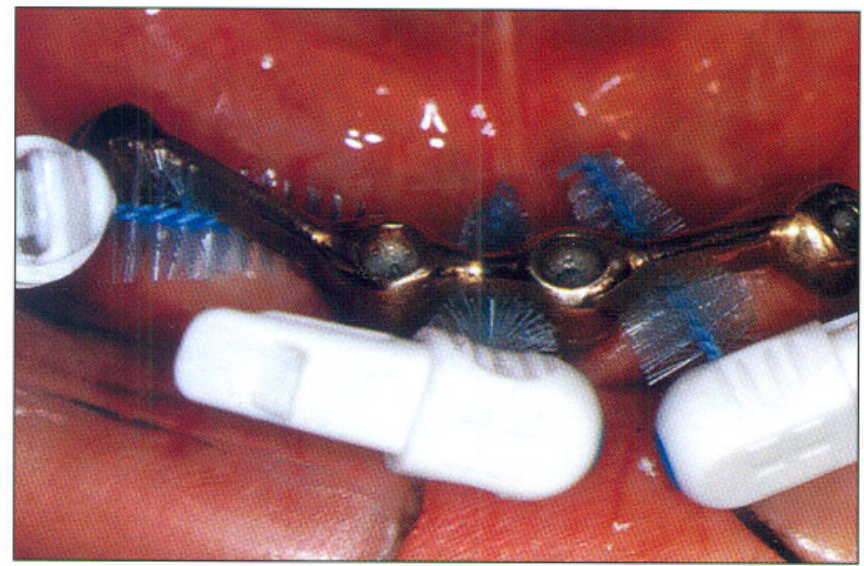

Fig. 7: Fase de higienización de los implantes por debajo de la barra de conexión.

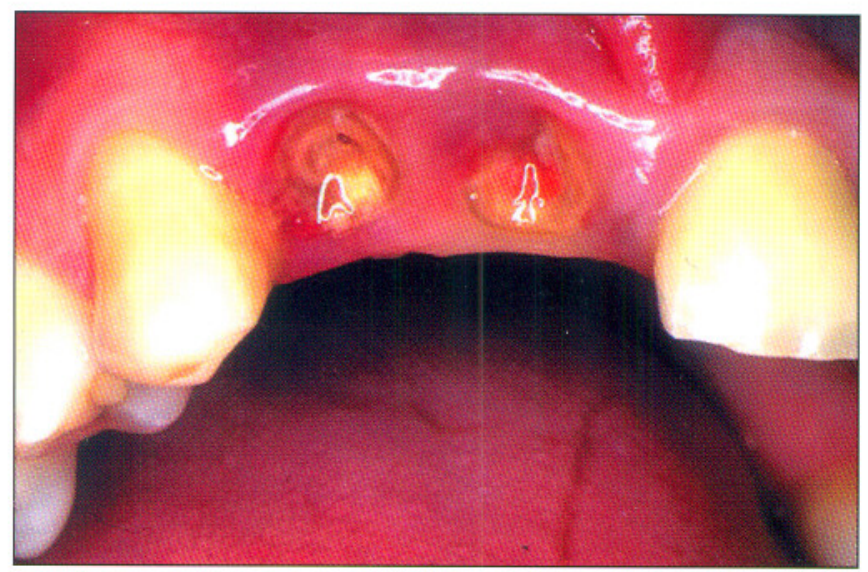

Fig. 8: 11 y el 12 tienen pronóstico imposible y no se pueden mantener (Caso clínico $\left.n^{\circ} 2\right)$.

to del estudio tiene un intervalo de tiempo comprendido desde los 6 meses asta los 3 años tras la intervención. Los pacientes han sido examinados entre los

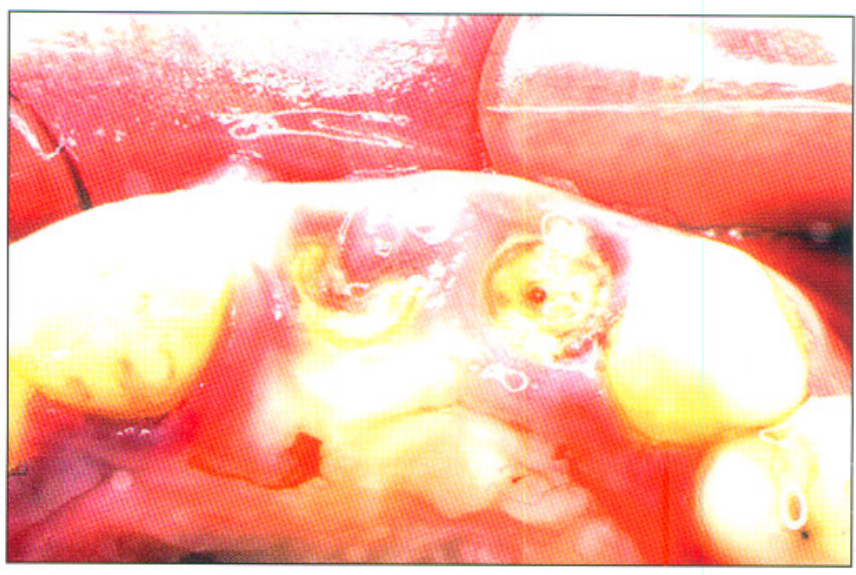

Fig. 9: Colocación del tornillo en los alvéolos (Caso clínico $n^{\circ} 1$ ).

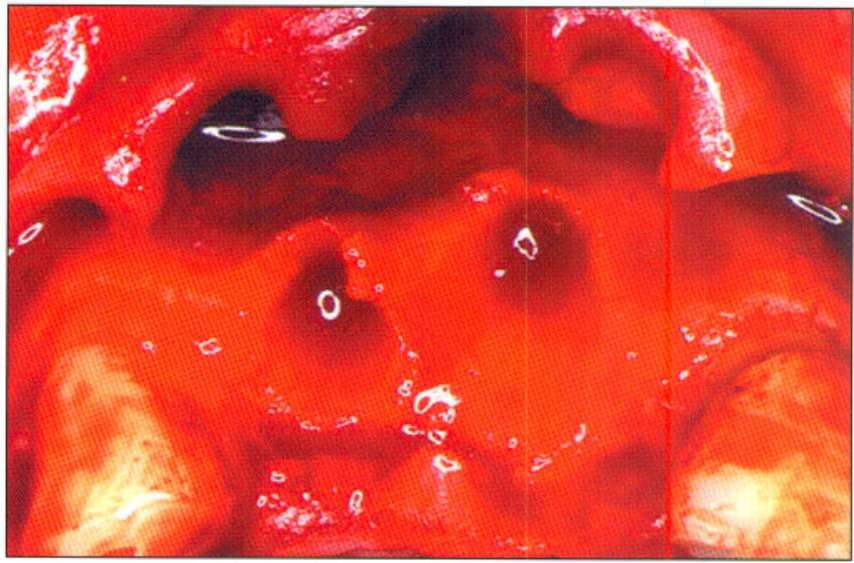

Fig. 10: Exodoncia atraumatica de los restos radiculares (Caso clíni$\operatorname{con} n^{\circ}$ ).

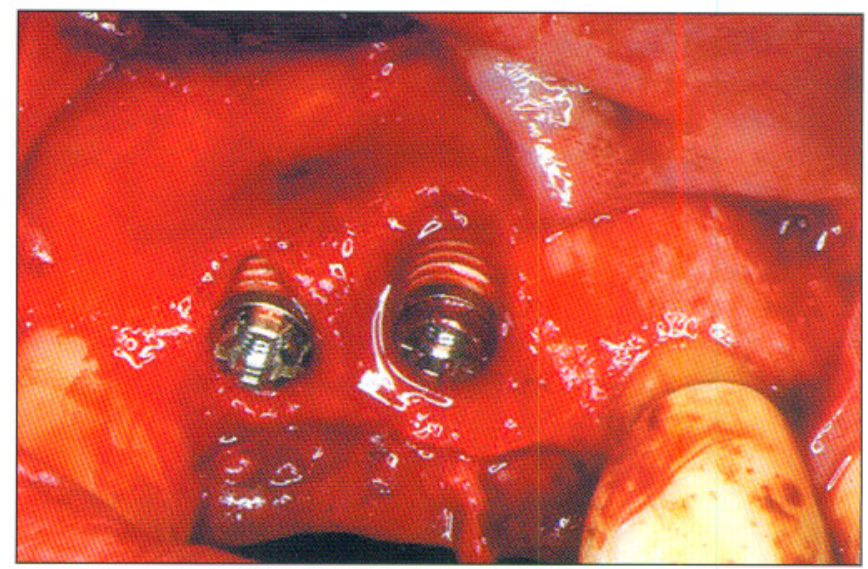

Fig. 11: Implante en posición 22 colocado hacia palatino por la reabsorción alveolar post extractiva.

7 y los 10 días tras la intervención, a la distancia de un mes, a los dos meses y a los seis meses para la realización de la prótesis. Desde la colocación de la próte- 


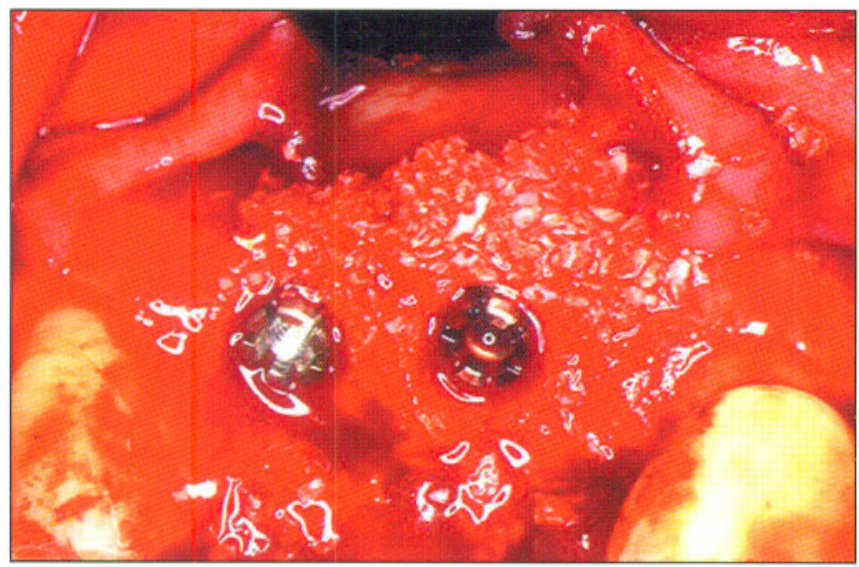

Fig. 12: Aplicación de hueso antólogo y eterólogo (Caso clínico $\left.n^{\circ} 2\right)$.

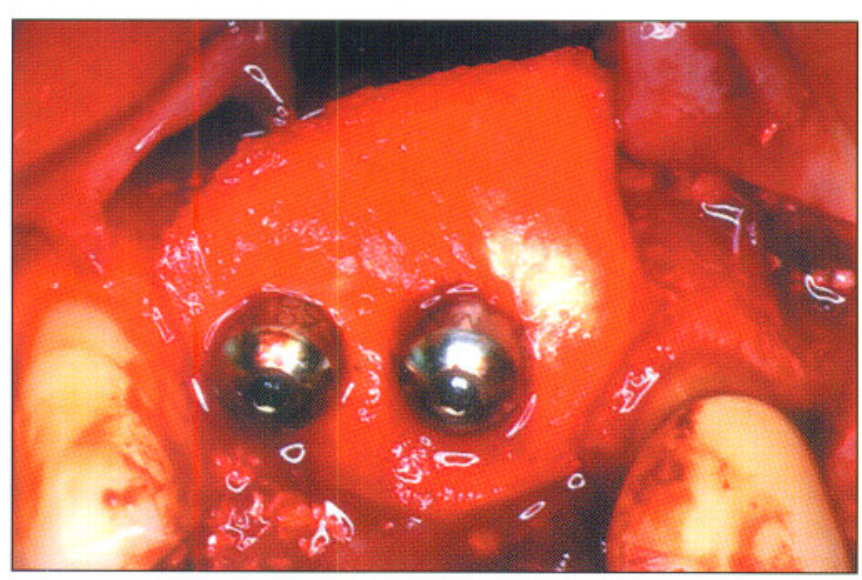

Fig. 13: Aplicación de membrana reasorbible (Caso clínico $n^{\circ}$ 2).

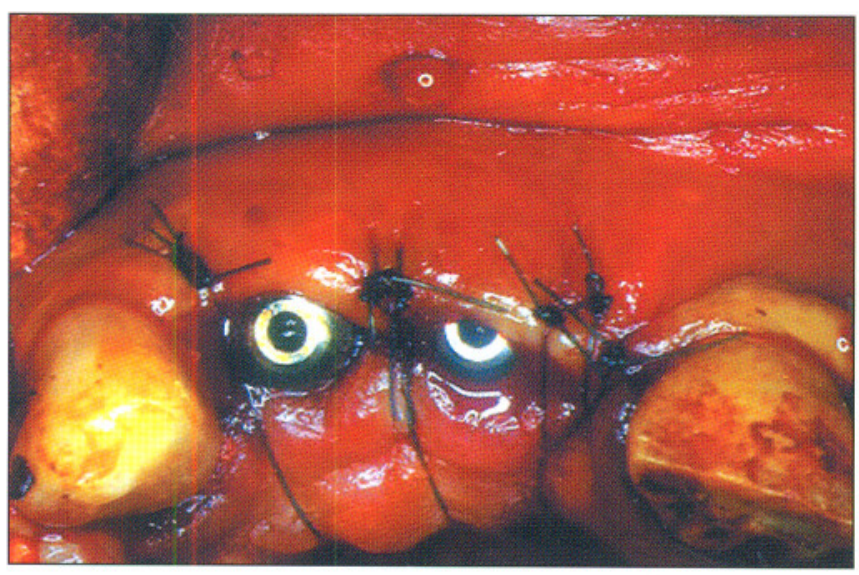

Fig. 14: Sutura (Caso clínico n $\left.{ }^{\circ} 2\right)$.

sis, los datos se tomaban, cada tres meses durante tres años. Hemos evaluado el porcentaje de éxito según los criterios propuestos por Albrektson y Buser a los

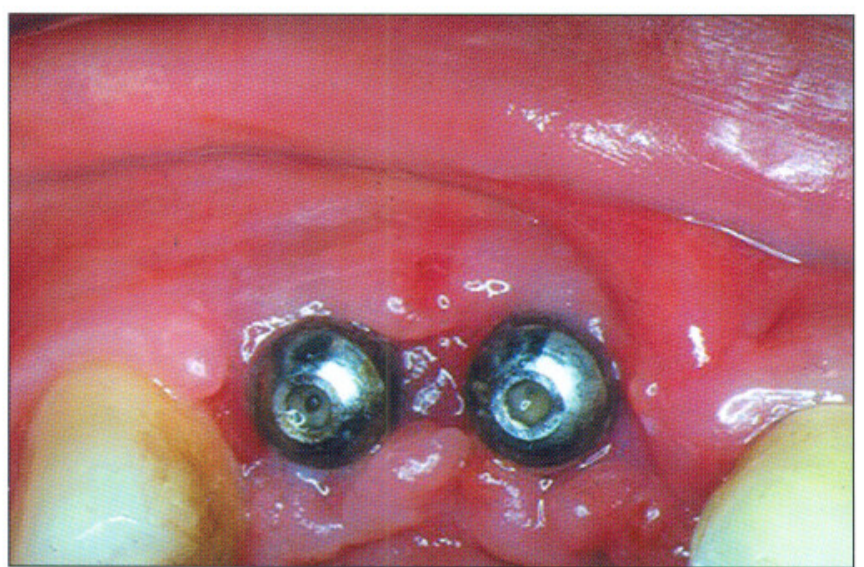

Fig. 15: Curación a los sietes días de la curación (Caso clínico n²).

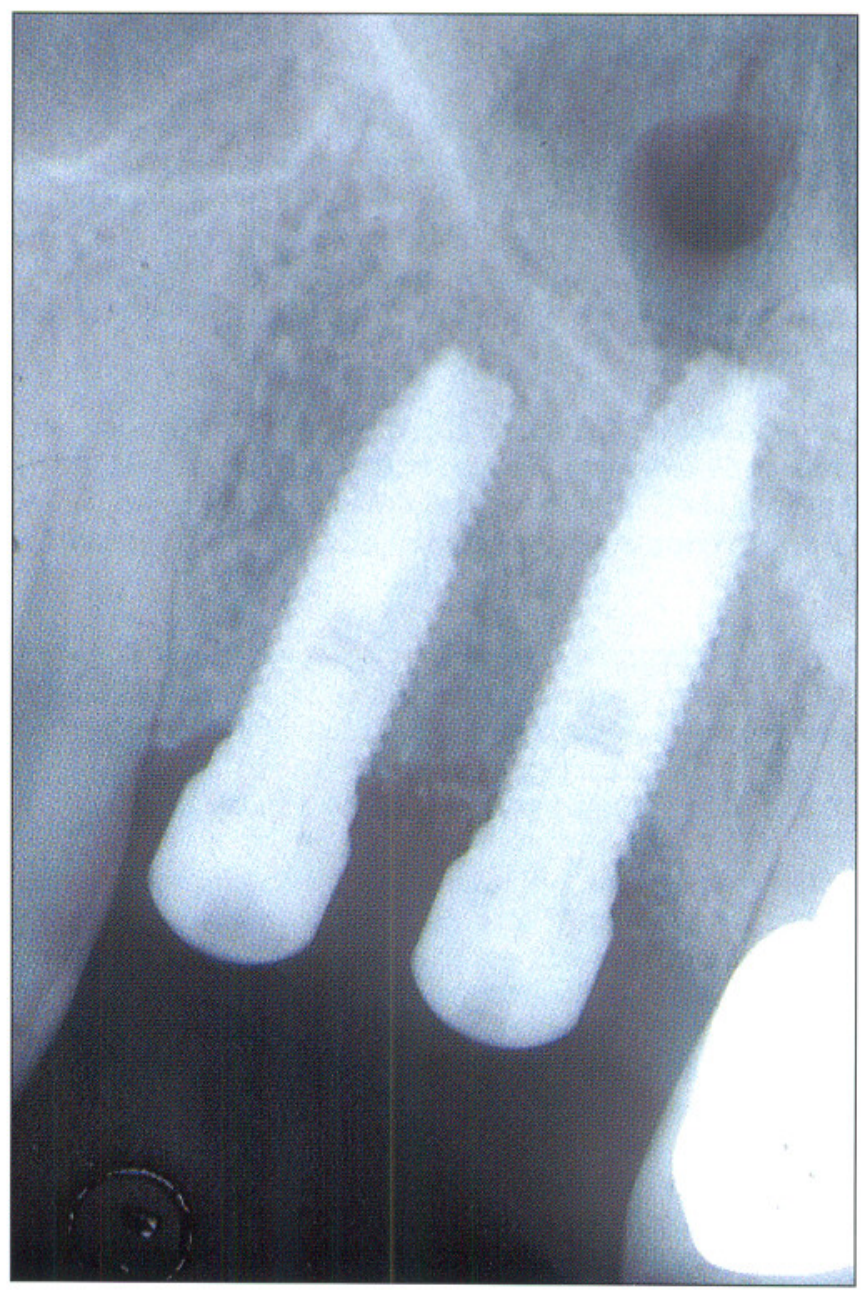

Fig. 16: Control radiográfico a los tres meses de la colocación del implante (Caso clínico $n^{\circ} 2$ ).

seis meses tras la colocación del implante (antes de la carga protésica), al año, a los dos años y a los tres años desde la carga protésica. 


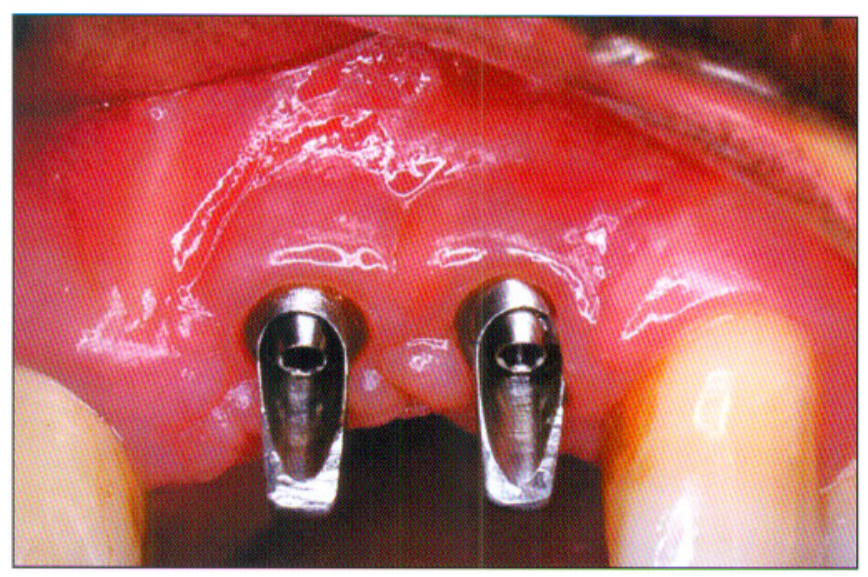

Fig. 17: Aplicación de los pilares protésicos.

\section{RESULTADOS}

Se han colocado 45 implantes con una técnica quirúrgica del tipo no sumergida con una sola fase quirúrgica con la siguiente distribución: 25 implantes en el arcada superior (20 en el sector anterior y 5 en los lateros-posteriores); 20 se han colocado a nivel mandibular (15 en las zonas latero-posteriores y 5 en las anteriores).

La evaluación del éxito de la terapia implantaria ha sido realizada según los criterios de Albrektson y Buser a los 6 meses (antes de la carga protésica), al año, a los dos años y a los tres años de la carga protésica.

De los 45 implantes colocados en la cavidad oral se ha evidenciado un fracaso en los primeros seis meses; otro fracaso se ha presentado a los dos años y medio después de la carga protésica (sobre 25 implantes con carga protésica y controlados a largo plazo).

Han sido cargados con prótesis 20 implantes: 16 con coronas unitarias 4 con prótesis removible con los implantes colocados en la región entre los agujeros mentonianos en la arcada inferior. El único fracaso que se ha manifestado en los primeros seis meses desde la colocación, era un implante que se había colocado junto a una membrana reabsorbible y hueso de tipo bovino, mientras que el implante que se ha perdido tras dos años desde la carga protésica había sido colocado solo con el auxilio de hueso bovino.

Desde estos resultados, aunque corresponden a un número contenido, parece que no es imprescindible el uso de membranas y de hueso heterólogo para aumentar los porcentajes de éxito. El diseño y la forma del implante no han modificado el porcentaje de osteointegración, aunque si parece claro que una forma del implante más congruente posible con el

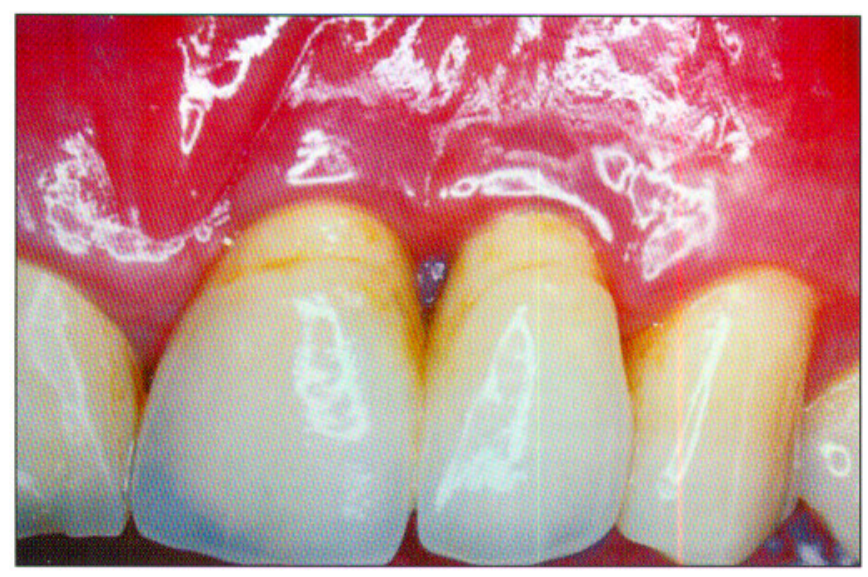

Fig.18: Restauración protésica terminada.

alveolo post-extractivo (implante de forma cónica), parece ser mejor para alcanzar más facilmente una estabilidad primaria, conditio sine que non para alcanzar el éxito en la terapia implantológica del tipo post-extractivo $(11,12,13)$.

\section{DISCUSIÓN Y CONCLUSIONES}

Concluyendo se puede apreciar que la técnica quirúrgica e implantológica con el implante colocado en el alveolo de forma inmediata tras la avulsión del elemento dentario, si es realizada según un preciso y bien determinado protocolo quirúrgico, ofrece garantías de predictibilidad de éxito, del mismo nivel que las conseguidas con la técnica del la colocación del implante osteointegrado de la forma convencional.

\section{ABSTRACT}

BACKGROUND: The purpose of this work is to evaluate the clinic efficiency of the surgical protocol in relation to the immediate placement of the screw into a post- extractive alveolus.

MATERIALS AND METHODS: According to Albrekston and Buser's criterions, 45 implants which had been placed with the post-extractive technique were scored after 6 months and after 3 years since the placement of the dental implant.

RESULTS: The applied protocol has proven to be suitable, the rate of success compared with the traditional technique has been similar, with the advantages of 
reducing notoriously the time to rehabilitate occlusion and gaining aesthetics for the patient.

CONCLUSIONS: With this new surgical and implantologic protocol it can be guaranteed a high rate of success reducing the intervention phase while adding aesthetic, functional and occlusal advantages.

\section{KEY WORDS}

Implant, alveolus, aesthetics.

\section{CORRESPONDENCIA}

Dino Calzavara

Joaquín María López, 41-c $6^{\circ}$ piso, portal $n^{\circ} 5$

Madrid

Correo: dinclaz@hotmail.com

\section{BIBLIOGRAFÍA}

1. Adell R., Lekholm U., Rokler B., Branemark P.I.: A 15 year study of osseointegrated implants in the treatment of the edentulous jaw. J Oral Surg 1981; 10: 387

2. Lazzara R.: Immediate implant placement into extraction sites: surgical and restorative advantages. Int. J Periodont Rest Dent 1989; 9: 333

3. Misch C.E.: Density of bone: effect on treatment plans, surgical approach, healing and progressive bone loading. Int. Oral Implantol 1990; 6: 23-31

4. Atwood D.A.: Postextraction change in the adult mandible as illustrated by microradiographs of mid-sagitals sections and serial cephalometric roentgenograph. J Prosthet Dent 1963; 13: 810
5. Becker W., Becker B.E.: Guided tissue regeneration for implants placed into extraction sockets and for implants deishence: Surgical tecnique and case reports. Int J Periodont Rest Dent 1990; 10: 377

6. Lang N.P., Bragger U., Hammerle C.H.F., Sutter F.: Immediate transmucosal implants using the principle of guided tissue regeneration. Clin Oral Impl Res 1994; 5: 154-63

7. Becker W., Dahlin C., Becker B.E., Lekolm U.: The use of ePTFE barrier membranes for bone promotion around titanium implants placed into extraction sockets.A prospective multicenter study. Int J Oral Maxillofacial Implants 1994; 9: 31-40

8. Gotfredsten K., Nimb L., Hjorting-Hansen E.: Immediate placement using a biodegradable barrier, polyhydroxibutyrate-hydroxivalerate reinforced with poliglactin 910 . An experimental study in dogs. Clin Oral Impl Res 1994; 5: 83-91

9. Leghissa G.C., Assenza B.: Impianti post-estrattivi protetti con Liodura umana. Il Dentista Moderno 1991; 1: 147-53

10. Buser D., Weber H.P., Lang N.P.: Tissue integration of non submerged implants 1 year results of a prospective study with 100 I. T.I hollow cyilinder and hollow screw implants. Clin. Oral. Impl. Res 1990; 1: 33-40

11. Bergglundh T., Lindhe J., Ericsson I., Marinello C.P.: The soft tissue barrier at implants and teeth. Clin. Oral Impl. Res 1991; 2: 81-90

12. Nyman J., Lang N.P., Buser D.: Bone regeneration adyacent to titanium dental implant using guided tissue regeneration: a report of two cases. Int. J. of Oral and Maxillofacial implants 1990; 5: 9-14

13. Becker W., Becker B.E.: A comparison of PTFE membranes alone or in combination with platelet-devired growth factors, and insulin or demineralized freeze-dried bone in promoting bone around immediate sockets implants. J. Periodontology 1999; 63: 929-40 
